\title{
Predictors of Severe Problematic Internet Use in Adolescent Students
}

\author{
Andrea Lukács \\ Faculty of Healthcare, University of Miskolc, 3515 Miskolc-Egyetemváros, Hungary \\ ORCID: 0000-0002-1938-8071
}

Received: 4 Apr 2021

Accepted: 27 Apr 2021

\begin{abstract}
Recent literature draws attention to the fact that problematic Internet use is a growing health issue among adolescents worldwide. This study aimed to find the potential demographic, physical and psychopathological risk factors associated with severe problematic Internet use of adolescents. A total of 1,347 adolescents (45.1\% males) were recruited from five high schools in three settlements. Students completed an online questionnaire and provided data about socio-demographics, physical activity, physical and psychopathological health, as well as about their Internet use habits (Problematic Internet Use Questionnaire). $1.9 \%$ of the respondents appeared to be severe, $20.4 \%$ moderate problematic Internet users. The complexity of the problem is manifested in the multifaceted relationships of factors. The multinomial regression analysis identified four significant risk factors for severe problematic internet use, namely depressive symptoms, loneliness, low level of father's education level and low level of physical activity. The real severe problematic Internet use is not so common in adolescent students, however, together with moderate problematic Internet users, this number has significance. Psychopathological factors such as elevated depressive symptoms and loneliness should be considered when preventive programs are implemented and more attention should be taken on physical activity as an effective tool against addictive behavior.
\end{abstract}

Keywords: adolescents, depressive symptoms, loneliness, physical activity, problematic Internet use

\section{INTRODUCTION}

Young people use the Internet as an integral part of their daily life with its advantages and disadvantages. Zoomers, or Generation $Z$ have grown up in digital environment, have access to various smart electronic devices and can access Internet almost universally. According to the Internet Stats and Facebook Usage in Europe June 2019 Statistics, 89\% of the Hungarian population is Internet user, especially adolescents and young adults (https://www.internetworldstats.com/stats4.htm). It is expected that proportion of problematic Internet users will increase as the Internet in general is expanding. Based on the latest literature, there is evidence that a minority of adolescents shows problematic patterns of Internet use, leading to detrimental effects for the users (Anderson et al., 2017; Xu et al., 2014). First, Ivan Goldberg psychiatrist drew attention to this maladaptive behavior in 1995 and called it "Internet addiction disorder" (later redefined as "pathological Internet-use disorder"), and put the diagnostic criteria (Wallis, 1997), however, it is still not mentioned in the Diagnostic and Statistical Manual of Mental Disorders, $5^{\text {th }}$ edition (DSM-5) (In Appendix, Internet Gaming Disorder as behavioral addiction was included for further empirical and clinical discussion). Young $(1996,1998)$ and Griffiths (1996) investigated this pathological problem in more depth and used term "Internet addiction" (IA). There is a great debate about the terminology. There is a widespread use of excessive Internet use, compulsive Internet use, Internet addiction, pathological Internet use, Internetrelated disorders, problematic Internet use, and scientists use them interchangeably. In this study, problematic Internet use (PIU) was utilized for describing adolescents' behaviour for two reasons. First, the 
concept of IA is not fully conceptualized; second, as a result of it, the cut-off point for addictive behavior is not or not clearly defined.

A series of studies draw attention to the complexity of the PIU. It is often comorbid with other psychiatric disorders (Ho et al., 2014; Ko et al., 2012; Reed et al., 2015), physical health (Tsitsika et al., 2016) and a variety of psychological comorbidities (Adalier \& Balkan, 2012). Besides that, studies indicated that PIU was associated with social isolation (Ang et al., 2012), low social support (Prievara et al., 2019), low self-esteem (Wiederhold, 2016; Yang \& Tung, 2007), improper eating habits (Gür et al., 2015), sleeping problems (Punamaki et al, 2007), cognitive defection (Park et al., 2011), poor interpersonal relationships (Milani et al., 2009), dissatisfaction with life (Van den Eijnden et al., 2008), and low physical activity (PA) (Durkee et al., 2016; Peltzer et el., 2014). Kuss and Griffiths (2012) in their systematic literature review with 18 studies used neuroimaging techniques concluded that Internet and gaming addiction led to functional and structural changes of brain that makes this problem especially serious in adolescents. Since adolescents are in the process of physical, emotional and cognitive development they are considered vulnerable population to the adverse effects of the Internet (Hurd et al., 2014; Kuss et al., 2014; Leung, 2007; Luengo Kanacri et al., 2014).

According to meta-analysis of Cheng and Li (2014), the prevalence of IA is estimated 6\% [95\% Cl: 5.1-6.9] globally. High ( $20 \%$ ) prevalence is observed in Asia where IA has great public concern (Adams, 2016). Kuss et al. (2014) found $0.8 \%$ prevalence rate in Italy and $26.7 \%$ in Hong Kong in adolescents. Durkee et al. (2012) evaluating almost 12 thousands adolescents in 11 European countries found this number approximately $4.4 \%$ including Hungary (1.6\%), and this study also demonstrated high variation by countries. There is evidence this problem exists and has negative consequences, and the prevalence of PIU is increasing among European adolescents, further research is required to consider it as a full disorder (Kaess et al., 2016).

Taking into account the growing prevalence and the wide range of factors that characterize the PIU, as well as the uncertainty in the complex official formulation of the problem (APA, 2013), this study aims to examine the potential demographic, physical and psychopathological risk factors associated with severe PIU of Hungarian adolescents in the Northeast region using the 18-item Problematic Internet Use Questionnaire (PIUQ).

\section{METHODOLOGY}

\section{Procedure and Ethics}

Students attending grade 9-12 were recruited from five high schools of three settlements in the Northeast region of Hungary. All students were invited to take part in the study. Parents were informed about the purpose and procedure of the study and voluntary nature of the participation via electronic logbook. Parents could give their consent using this official electronic documentation. Students completed an online battery of standardized questionnaires in the school that took approximately 15 minutes. All the students were eligible who were present on the survey day, had their parents' consent, and showed a willingness to complete the questionnaire clicking the consent button before starting the online survey. The research project was approved by the Borsod-Abaúj-Zemplén Regional Ethics Committee and the Institutional Ethics Committee of the University of Miskolc, and the managements of all high schools agreed to collect data.

\section{Participants}

Of the 1391 students taking part in the survey, data for 44 respondents were dropped out because of the incomplete responses. The final sample included 1347 participants. Descriptive statistics of the participants are presented in Table 1. 
Table 1. Demographics of participants $(M=1349)$

\begin{tabular}{ll}
\hline Mean (SD), percentage & Adolescent students \\
\hline Sample & 1347 \\
Age (years) & $16.49(1.46)$ \\
Sex - males : females : M/D & $45.1: 54.3: 0.6$ \\
Financial situation - below : average : above : M/D & $2.7: 84.0: 12.8: 0.5$ \\
Mother's education - lower than secondary: secondary : higher than secondary : M/D & $6.6: 47.6: 38.9: 6.9$ \\
Father's education - lower than secondary: secondary : higher than secondary : M/D & $6.5: 52.1: 29.9: 11.5$ \\
\hline
\end{tabular}

M/D - missing data

\section{Outcome Measures}

Sociodemographic. Students provided data about their age, sex, mothers and fathers' education level (lower secondary education, secondary education, higher then secondary education), financial situation of their family (below average, average, above average) as well as their weight and height for calculating BMI.

Problematic internet use. PIU was assessed by the 18-item Problematic Internet Use Questionnaire (PIUQ) developed by Demetrovics et al. (2008) using factor and psychometric analysis. The questionnaire consists of three six-item factors, namely obsession (being obsessed with internet activities and mental withdrawal symptoms caused by the lack of internet activity (Koronczai et al., 2011), neglect (neglecting non-Internet activities), and control disorder (unable stopping to use the Internet). Items were rated on a 5-point Likert scale from never (1) to always (5). Chronbach's alpha in the study sample is 0.86 indicating good internal consistency (Nunnally, 1994). There are no any cut-off points for when the internet use becomes of addictive concerns. Higher scores indicate more problems. For evaluating covariates, scores were trisected as no problem (18-41), moderate problem (42-65) and severe problem (66-90) in internet use. The validity and reliability of the PIUQ in adolescent and adult population is verified by Koronczai et al. (2011).

Social support. The Multidimensional Scale of Perceived Social Support (MSPSS) was used to evaluate subjectively assessed social support from family, friends and a significant other. The questionnaire comprised of a total of 12 items, with 4 items for each subscale on a 7-point Likert scale from very strongly disagree (1) to very strongly agree (7). Higher mean scores reflect high support (Zimet et al., 1988). Hungarian validation was conducted by Papp-Zipernovszky et al. (2017). Chronbach's $\alpha=.91$ in this study population.

Well-being. WHO-5 Well-Being Index was used to evaluate students' emotional profile (WHO, 1998; Topp et al., 2015). Answers were reverse-scored and linearly transformed to a 0-100 scale. All scores were calculated by dividing the sum of the items and the number of items answered. The higher scores refer to better wellbeing. The index has previously been validated for Hungarian usage (Susánszky et al., 2002) (Chronbach's $\alpha$ $=.79)$.

Loneliness. Adolescent students' loneliness was evaluated using the UCLA Loneliness Scale. This scale contained questions measuring three dimensions of loneliness: relational and social connectedness, as well as self-perceived isolation. The possible answer categories are hardly ever (1), some of the time (2) and often (3). Higher summed score indicated more loneliness (Hughes et al., 2004). Internal consistency of the questionnaire in our sample was Chronbach's $\alpha=0.85$.

Depression. 6-item Kutcher Adolescent Depression Scale is a psychological self-rating scale to assess depressive symptoms in adolescents. Scores on the test range from 0 to 18 , higher scores indicate more severe current depressive symptoms (Brooks et al. 2003; LeBlanc et al., 2002) (Chronbach's $\alpha=.78$ ).

Self-esteem. The Rosenberg's Self-Esteem Scale was used to evaluate students' self-esteem (Rosenberg, 1965). It has ten items of which five are reversed scored. Respondents answered on a 4-point Likert scale (from strongly agree to strongly disagree). Higher scores indicate higher self-esteem. Cronbach's $\alpha$ was found .77 in this study population.

Life satisfaction. Satisfaction with Life Scale by Diener et al. $(1985,2013)$ is a five-item questionnaire assessing the subjective experience of satisfaction with the life as a whole. Respondents can indicate their 
degree of agreement with the statements on a 7-point scale from 1 (unsatisfied) to 7 (satisfied). The score on the scale is given by summing the responses to the items, with a higher score indicating higher life satisfaction (Chronbach's $\alpha$ in this population is .80). Hungarian adaptation of the scale was performed by Martos et al. (2014).

Perceived health status and anxiety. Perceived health and anxiety was displayed using Visual Analog Scale (VAS) of 0 to 100, where 0 represents "worst imaginable health"/"not at all anxious" and 100 indicates "best imaginable health." /"most anxious".

Physical activity. PA was measured with an item, where adolescents were asked to report the number of days over the previous week during which they were physically active for a total of at least 60 minutes that increases the heart rate and makes them get out of breath some of the time. Answers ranged from 0 to 7.

\section{Statistical Analysis}

SPSS statistical software (IBM Corp. Released 2019. IBM SPSS Statistics for Windows, Version 26.0. Armonk, NY, USA) was used for analysis. Significance level at $p \leq 0.05$ was accepted. Descriptive statistics reported median and interquartile range (IQR), or mean and SD for quantitative variables, and proportion for qualitative variables. Cronbach's alphas were calculated to estimate internal consistency of scales used in the study. Due to violation of normality in PIUQ scores, bivariate correlation was illustrated by Spearman's coefficient $(\mathrm{Sr})$. Multinomial regression was applied to create predictions to determine which sociodemographic psychologic and physical health variables predict severe PIU. In the logistic model, the reference category $(Y=0)$ was the group without problems of internet use and the other two categories $[Y=1$ (moderate) and $\mathrm{Y}=2$ (severe problem in internet use)] were compared to this group. Explanatory variables included categorical (sex, financial situation, physical activity level, mother's and father's education level) and continuous variables (age, social support, self-esteem, well-being, depressive symptoms, anxiety, loneliness, overall life satisfaction, perceived health status). Variable selection and model fitting were performed following Hosmer's approach (2013). Multicollinearity was checked with variance inflation factors (VIF), all variables were between $1.027-2.038$.

\section{RESULTS}

\section{Adolescents' Internet Use}

$1.9 \%$ of the participants are considered severe, whereas, $20.4 \%$ are considered moderate problematic Internet users without sex difference $\left(\chi^{2}=1.67, \mathrm{df}=2 ; \mathrm{p}=.43\right)$. Adolescent students had a median score of 31 (IQR 14) [obsession: 9 (IQR 5), neglect: 11 (IQR 6), control disorder: 11 (IQR 6)]. Regarding the group with severe PIU, the PIUQ median score was 68.5 (IQR 8.25), [obsession: 24 (IQR 5.25), neglect: 24 (IQR 4), control disorder: 23 (IQR 5.5)]. The most common problem for students were sleep deprivation, spending more time online than expected, neglect of household chores, and unable to reduce time spent online.

\section{Inter-Correlation of the Variables}

In general, increase in PIUQ score was significantly associated with decrease in physical activity level, perceived health status, well-being, life satisfaction, social support in general, self-esteem, as well as increase in loneliness and depressive symptoms. Age (13-22) did not show any correlations with scores. Depressive symptoms significantly correlated with anxiety, age, PA level, perceived health status, social support, life satisfaction, loneliness, well-being and self-esteem. Table $\mathbf{2}$ presents inter-correlations of the variables. 
Table 2. Inter-correlations of the variables

\begin{tabular}{|c|c|c|c|c|c|c|c|c|c|c|}
\hline Variables & 1 & 2 & 3 & 4 & 5 & 6 & 7 & 8 & 9 & 10 \\
\hline 1 PIU score & 1 & & & & & & & & & \\
\hline 2 Age & .02 & 1 & & & & & & & & \\
\hline 3 PA level & $-.16^{* * *}$ & $-.08^{* *}$ & 1 & & & & & & & \\
\hline 4 Percieved health & $-.18^{* * *}$ & $-.09^{* *}$ & $.18^{* * *}$ & 1 & & & & & & \\
\hline 5 Social support & $-.28^{* * *}$ & $-.08^{* *}$ & $.18^{* * *}$ & $.26^{* * *}$ & 1 & & & & & \\
\hline 6 Life satisfaction & $-.22^{* * *}$ & $-.14^{* * *}$ & $.22^{* * *}$ & $.45^{* * *}$ & $.52^{* * *}$ & 1 & & & & \\
\hline 7 Loneliness & $.29^{* * *}$ & $.13^{* * *}$ & $-.15^{* * *}$ & $-.29^{* * *}$ & $-.48^{* * *}$ & $-.45^{* * *}$ & 1 & & & \\
\hline 8 Well-being & $-.21^{* * *}$ & $-.09^{* *}$ & $.26^{* * *}$ & $.36^{* * *}$ & $.33^{* * *}$ & $.51^{* * *}$ & $-.39^{* * *}$ & 1 & & \\
\hline 9 Self-esteem & $-.33^{* * *}$ & $-.07^{*}$ & $-.07^{*}$ & $.33^{* * *}$ & $.45^{* * *}$ & $.50^{* * *}$ & $-.51^{* * *}$ & $.46^{* * *}$ & 1 & \\
\hline 10 Anxiety & -.08 & $-.06^{*}$ & $-.06^{*}$ & $.15^{* * *}$ & $.09^{* *}$ & $.11^{* * *}$ & $-.12^{* * *}$ & $.07^{*}$ & $.14^{* * *}$ & 1 \\
\hline 11 Depressive symptoms & $.34^{* * *}$ & $.14^{* * *}$ & $-.14^{* * *}$ & $-.38^{* * *}$ & $-.42^{* * *}$ & $-.53^{* * *}$ & $.56^{* * *}$ & $-.57^{* * *}$ & $-.60^{* * *}$ & $-.11^{* * *}$ \\
\hline
\end{tabular}

Note: ${ }^{*} p<.05 ; * * p<.01 ; * * * p .001$

Table 3. Logistic regression predicting likelihood of severe problematic internet use

\begin{tabular}{lccccc}
\hline & & \multicolumn{3}{c}{$95 \% \mathrm{Cl}$ for OR* } \\
Variables & $\mathrm{B}(\mathrm{SE})$ & Lower & OR & Upper & Sig. \\
\hline Depressive symptoms & $.24(.08)$ & 1.10 & 1.27 & 1.47 & .001 \\
Loneliness & $.38(.13)$ & 1.14 & 1.46 & 1.88 & .003 \\
Father's education level (0)** & $1.79(.74)$ & 1.39 & 5.97 & 25.63 & .016 \\
Physical activity level & $-.25(.12)$ & .61 & .78 & .98 & .036 \\
\hline
\end{tabular}

*95\% Confidence Interval for Odds Ratio

$* * 0=$ less than secondary education

\section{Predicting Likelihood of Severe Problematic Internet Use}

Multinomial logistic regression (MLR) was undertaken to explore estimation of the net effects of a set of explanatory variables on the dependent variable (severe PIU). The Likelihood Ratio chi-square test $\left(\chi^{2}{ }_{(34)}=\right.$ $181.09, p<.001$ ) indicated that the final logistic model was statistically significant, and $75.0 \%$ of cases were correctly classified. Parameter estimation referred four factors (depressive symptoms, loneliness, father's education level and physical activity level) contributed meaningfully to the full effect (Table 3).

\section{DISCUSSION}

This study investigated explanatory variables of severe PIU in adolescents in the Northeast region of Hungary. Since diagnostic criteria were not established and the applied questionnaire had no clinically relevant cut-off points for determine IA, three groups were formed based on continuum of PIUQ scores. Results demonstrated low prevalence of risky behavior that is in line with earlier study including Hungarian adolescents using different measure (Durkee, 2012). It should be mentioned there is still no widely acceptable measure to determine PIU, and data with different variances about the prevalence of PIU provided by various studies, leave uncertainty behind them, primarily for different assessment tools, different cut-off points even when using the same measurement, and different social and cultural context (Kuss et al., 2014; Mamun \& Griffiths, 2019).

Some studies identified sex difference, males tended to be at risk for developing addiction (Lam et al., 2009; Tsitsika et al., 2009). This study cannot confirm this finding; it is in line with Khazaal's (2008) and Wang's (2011) results that sex is not a real risk factor for PIU. Both sexes equally need to take part in prevention programs against PIU.

Findings of this study revealed four factors included depressive symptoms, loneliness, father's education level and physical activity level that explained the relationship between the severe PIU and a set of variables including socio-demographic, physical, and psychological variables. It is well-known, depressive symptoms are common in adolescence. Result of this study is in agreement with other studies indicated positive 
association between PIU and depression in adolescents (Saikia et al, 2019; Yang et al, 2014). This relationship is also demonstrated in university students (Akin \& Iskender, 2011), and in general population (Morrison \& Gore, 2010). As this study design was not appropriate to determine the casualty effect, this effect likely works as a vicious cycle resulting PIU, which further generates depression. The relationship between depressive symptoms and PIU appears to be bi-directional, as a precursor and predictor (Ciarrochi et al., 2016; Dong et al., 2011; van den Eijnden et al., 2008), and there is evidence about its association with loneliness (Mahon et al., 2006). Vanhalst's longitudinal study (2012) revealed that loneliness is more consistent predictor of depressive symptoms than vice versa indicating that loneliness predicts later depressive symptoms. Erzen and Çikrikci's meta-analysis (2018) also confirms effect of loneliness on depression assessing different population. Adolescents with psychopathological symptoms are prone to use internet in excessive and compulsive way as they find relief in the cyber world on their problems they cannot cope with (Caplan, 2003). However, directionality of depression and loneliness in this study cannot be addressed with PIU, their clinical treatment seems to be important step in the fight against PIU.

Noteworthy is the observation that fathers of adolescents with severe PIU have low education level. Studies indicate low level of parental monitoring (Brighi et al., 2019; Khurana et al., 2015) and increased parent-child conflict as risk factors for PIU (Siomos et al., 2012) while good parental communication can lower the risk (van den Eijnden et al., 2010; Yu \& Shek, 2013). Only a few studies indicate association between risks for PIU and low level of parental education. Chandrima et al. (2020) found association between PIU and lower education level of both parents explaining this result with dysfunctional family environment where adolescents used Internet as a maladaptive avoidance strategy. It is conceivable that any negative effects the children experiences from the paternal side can push them maladaptive behavior. Generally, the influence of father has a greater emphasis on parenting than mother. Father with lower intellectual abilities has a narrow spectrum of leisure activities that can affect the family members' everyday life. Potential explanation might be the environmental factors when parents with lower education are less aware of disadvantages and negative effect of Internet use and as a result, the parental control is missing. Protective effect of parental monitoring for younger and older adolescents of both sexes was confirmed by previous studies (Brighi et al., 2019; Khurana et al., 2015).

Another explanatory factor of severe PIU was physical activity which can be a way out of the problem. A child engaged with physical activity reduces the amount of time spent online. The data of an American study evaluating 2108 college students showed negative association between time spent on internet use and physical activity (Derbyshire et al., 2013). Another study evaluating adolescents and young adults from the Arabian Gulf Culture also found that moderate and mild physical activity were negatively associated with PIU (Bener et al., 2013). The recent paper about the Turkish high school students found lower rate of PIU in students who performed physical activities at least 2 days a week (Sayll et al., 2021). This relationship between physical activity and PIU should be considered when developing prevention programs, or even more a treatment program. It seems an applicable tool against PIU and other addictive behavior (Lynch et al., 2010).

Despite the relatively large sample size and the use of validated measure, some limitations should be mentioned. This study cannot make definitive claims about causality due to cross-sectional study design. Since the subjects are limited to the Northeast region of the country, the results cannot be generalized to the whole Hungarian adolescent population. Furthermore, physical activity, which has become an explanatory factor of PIU, was measured with a single item, that is widely used in research studies (O'Halloran et al., 2020). To avoid method bias in applying single item measures, students were motivated to give accurate answers to the questions. Single item questions were clear and easy to complete, however frequency of PA was retrospectively self-reported making it prone to recall bias (Podsakoff et al., 2012).

\section{CONCLUSION}

In this paper broad range of variables were examined, including socio-demographics, psychological health and physical activity to find the associated factors with PIU in adolescents. The complexity of the problem is manifested in the multifaceted relationships of factors, only four of them (depressive symptoms, loneliness, 
father's education level and physical activity) predicted likelihood of severe PIU in a relatively large sample size. Contrary to the claims of other studies, relatively low number of students proved highly problematic internet users, however, together with moderate problematic internet users, this number has significance. Only a few studies indicated the parents' low education level as a risk factor for PIU, perhaps because it was not in the focus of research. Family environment seems an important factor investigated maladaptive behavior. PA has also been less studied. There is indisputable evidence that higher level of PA prevents against several chronic diseases, maintains favorable well-being, and it seems an effective tool in the primary and secondary prevention against abnormal psychological behaviors such as PIU. In order to promote the health of these populations, further investigation can provide interventions how to implement increased physical activity in prevention of PIU in education institutions.

Funding: The author received no financial support for the research and/or authorship of this article.

Declaration of interest: Author declares no competing interest.

Acknowledgements: Assistance of Ibolya Hudák is highly appreciated in data collection in the secondary educational institutes. Data availability: Data generated or analysed during this study are available from the author on request.

\section{REFERENCES}

Adalier, A., \& Balkan, E. (2012). The relationship between Internet addiction and psychological symptoms. International Journal of Global Education, 1(2), 42-49.

Adams, M. (2016). Internet addiction: prevalence, risk factors and health effects. Adams, Margaret E. Hauppauge, New York. ISBN 9781536104363. OCLC 961923990.

Akin, A., \& Iskender, M. (2011). Internet addiction and depression, anxiety, and stress. International Online Journal of Educational Sciences, 3(1), 138-148.

American Psychiatric Association. (2013). Diagnostic and Statistical Manual of Mental Disorders (DSM-5). https://www.psychiatry.org/psychiatrists/practice/dsm

Anderson, E. L., Steen, E., \& Stavropoulos, V. (2017). Internet use and Problematic Internet Use: A systematic review of longitudinal research trends in adolescence and emergent adulthood. International Journal of Adolescence and Youth, 22(4), 430-454. https://doi.org/10.1080/02673843.2016.1227716. S2CID 152003110

Ang, R. P., Chong, W. H., Chye, S., \& Huan, V. S. (2012). Loneliness and generalized problematic Internet use: Parents' perceived knowledge of adolescents' online activities as a moderator. Computers in Human Behavior, 28(4), 1342e1347. https://doi.org/10.1016/j.chb.2012.02.019

Bener, A., \& Bhugra, D. (2013). Lifestyle and depressive risk factors associated with problematic internet use in adolescents in an Arabian Gulf culture. Journal of Addiction Medicine, 7(4), 236-242. https://doi.org/10.1097/ADM.0b013e3182926b1f

Brighi, A., Menin, D., Skrzypiec, G., \& Guarini, A. (2019). Young, bullying, and connected. common pathways to cyberbullying and problematic internet use in adolescence. Frontiers in Psychology, 10, 1467. https://doi.org/10.3389/fpsyg.2019.01467

Brooks, S. J., Krulewicz, S. P., \& Kutcher, S. (2003). The Kutcher Adolescent Depression Scale: assessment of its evaluative properties over the course of an 8-week pediatric pharmacotherapy trial. Journal of Child and Adolescent Psychopharmacology, 13(3), 337-349. https://doi.org/10.1089/104454603322572679

Caplan, S. E. (2003). Preference for online social interaction: A theory of problematic Internet use and psychosocial well-being. Communication Research, 30(6), 625-648. https://doi.org/10.1177/0093650203257842 
Ciarrochi, J., Parker, P., Sahdra, B., Marshall, S., Jackson, C., Gloster, A. T., \& Heaven, P. (2016). The development of compulsive Internet use and mental health: A four-year study of adolescence. Developmental Psychology, 52, 271-283. https://doi.org/10.1037/dev0000070

Chandrima, R. M., Kircaburun, K., Kabir, H., Riaz, B. K., Kuss, D. J., Griffiths, M. D., \& Mamun, M. A. (2020). Adolescent problematic internet use and parental mediation: A Bangladeshi structured interview study. Addictive Behaviors Reports, 12, Article 100288. https://doi.org/10.1016/j.abrep.2020.100288

Cheng, C., \& Li, A. Y. (2014). Internet addiction prevalence and quality of (real) life: a meta-analysis of 31 nations across seven world regions. Cyberpsychology, Behavior and Social Networking, 17(12), 755760. https://doi.org/10.1089/cyber.2014.0317

Demetrovics, Z., Szeredi, B., \& Rózsa, S. (2008). The three-factor model of Internet addiction: the development of the Problematic Internet Use Questionnaire. Behavior Research Methods, 40(2), 563574. https://doi.org/10.3758/brm.40.2.563

Derbyshire, K. L., Lust, K. A., Schreiber, L. R., Odlaug, B. L., Christenson, G. A., Golden, D. J., \& Grant, J. E. (2013). Problematic Internet use and associated risks in a college sample. Comprehensive Psychiatry, 54(5), 415-422. https://doi.org/10.1016/j.comppsych.2012.11.003

Diener, E., Emmons, R. A., Larsen, R. J., \& Griffin, S. (1985). The Satisfaction With Life Scale. Journal of Personality Assessment, 49(1), 71-75. https://doi.org/10.1207/s15327752jpa4901_13

Diener, E., Inglehart, R., \& Tay, L. (2013). Theory and validity of life satisfaction scales. Social Indicators Research, 112, 497-527. https://doi.org/10.1007/s11205-012-0076-y

Dong, G., Lu, Q., Zhou, H., \& Zhao, X. (2011). Precursor or sequela: Pathological disorders in people with Internet addiction disorder. PLoS One, 6, e14703. https://doi.org/10.1371/journal.pone.0014703

Durkee, T., Kaess, M., Carli, V., Parzer, P., Wasserman, C., Floderus, B., Apter, A., Balazs, J., Barzilay, S., Bobes, J., Brunner, R., Corcoran, P., Cosman, D., Cotter, P., Despalins, R., Graber, N., Guillemin, F., Haring, C., Kahn, J. P., Mandelli, L., ... Wasserman, D. (2012). Prevalence of pathological internet use among adolescents in Europe: demographic and social factors. Addiction (Abingdon, England), 107(12), 22102222. https://doi.org/10.1111/j.1360-0443.2012.03946.x

Durkee, T., Carli, V., Floderus, B., Wasserman, C., Sarchiapone, M., Apter, A., Balazs, J. A., Bobes, J., Brunner, R., Corcoran, P., Cosman, D., Haring, C., Hoven, C. W., Kaess, M., Kahn, J. P., Nemes, B., Postuvan, V., Saiz, P. A., Värnik, P., \& Wasserman, D. (2016). Pathological Internet Use and Risk-Behaviors among European Adolescents. International Journal of Environmental Research and Public Health, 13(3), 294. https://doi.org/10.3390/ijerph13030294

Erzen, E., \& Çikrikci, Ö. (2018). The effect of loneliness on depression: A meta-analysis. The International Journal of Social Psychiatry, 64(5), 427-435. https://doi.org/10.1177/0020764018776349

Griffiths, M. D. (1996). Internet addiction: An issue for clinical psychology? Clinical Psychology Forum, 97, 3236.

Gür, K., Yurt, S., Bulduk, S., \& Atagöz, S. (2015). Internet addiction and physical and psychosocial behavior problems among rural secondary school students. Nursing \& Health Sciences, 17(3), 331-338. https://doi.org/10.1111/nhs.12192

Ho, R. C., Zhang, M. W., Tsang, T. Y., Toh, A. H., Pan, F., Lu, Y., Cheng, C., Yip, P. S., Lam, L. T., Lai, C. M., Watanabe, H., \& Mak, K. K. (2014). The association between internet addiction and psychiatric comorbidity: A meta-analysis. BMC Psychiatry, 14, 183. https://doi.org/10.1186/1471-244X-14-183

Hosmer, D. W. Jr, Lemeshow, S., \& Sturdivant, R. X. (2013). Applied logistic regression (3rd Edn). John Wiley \& Sons. 
Hughes, M. E., Waite, L. J., Hawkley, L. C., \& Cacioppo, J. T. (2004). A short scale for measuring loneliness in large surveys results from two population-based studies. Research on Aging, 26(6), 655-672. https://doi.org/10.1177/0164027504268574

Hurd, Y. L., Michaelides, M., Miller, M. L., \& Jutras-Aswad, D. (2014). Trajectory of adolescent cannabis use on addiction vulnerability. Neuropharmacology, 76 Pt $B(0 \quad 0)$, 416-424. https://doi.org/10.1016/j.neuropharm.2013.07.028

Kaess, M., Parzer, P., Brunner, R., Koenig, J., Durkee, T., Carli, V., Wasserman, C., Hoven, C. W., Sarchiapone, M., Bobes, J., Cosman, D., Värnik, A., Resch, F., \& Wasserman, D. (2016). Pathological Internet use is on the rise among European adolescents. The Journal of Adolescent Health, 59(2), 236-239. https://doi.org/10.1016/j.jadohealth.2016.04.009

Khazaal, Y., Billieux, J., Thorens, G., Khan, R., Louati, Y., Scarlatti, E., Theintz, F., Lederrey, J., Van Der Linden, M., \& Zullino, D. (2008). French validation of the Internet Addiction Test. Cyberpsychology \& Behavior, 11(6), 703-706. https://doi.org/10.1089/cpb.2007.0249

Khurana, A., Bleakley, A., Jordan, A. B., \& Romer, D. (2015). The protective effects of parental monitoring and internet restriction on adolescents' risk of online harassment. Journal of Youth and Adolescence, 44(5), 1039e1047. https://doi.org/10.1007/s10964-014-0242-4

Ko, C. H., Yen, J. Y., Yen, C. F., Chen, C. S., \& Chen, C. C. (2012). The association between Internet addiction and psychiatric disorder: A review of the literature. European Psychiatry, 27(1), 1-8. https://doi.org/10.1016/j.eurpsy.2010.04.011

Koronczai, B., Urbán, R., Kökönyei, G., Paksi, B., Papp, K., Kun, B., Arnold, P., Kállai, J., \& Demetrovics, Z. (2011). Confirmation of the three-factor model of problematic internet use on off-line adolescent and adult samples. Cyberpsychology, Behavior and Social Networking, 14(11), 657-664. https://doi.org/10.1089/cyber.2010.0345

Kuss, D. J., \& Griffiths, M. D. (2012). Internet and gaming addiction: a systematic literature review of neuroimaging studies. Brain Sciences, 2(3), 347-374. https://doi.org/10.3390/brainsci2030347

Kuss, D. J., Griffiths, M. D., Karila, L., \& Billieux, J. (2014). Internet addiction: a systematic review of epidemiological research for the last decade. Current Pharmaceutical Design, 20(25), 4026-4052. https://doi.org/10.2174/13816128113199990617

Lam, L. T., Peng, Z. W., Mai, J. C., \& Jing, J. (2009). Factors associated with Internet addiction among adolescents. Cyberpsychology \& Behavior, 12(5), 551-555. https://doi.org/10.1089/cpb.2009.0036

LeBlanc, J. C., Almudevar, A., Brooks, S. J., \& Kutcher, S. (2002). Screening for adolescent depression: comparison of the Kutcher Adolescent Depression Scale with the Beck depression inventory. Journal of Child and Adolescent Psychopharmacology, 12(2), 113-126. https://doi.org/10.1089/104454602760219153

Leung L. (2007). Stressful life events, motives for Internet use, and social support among digital kids. Cyberpsychology \& Behavior, 10(2), 204-214. https://doi.org/10.1089/cpb.2006.9967

Luengo Kanacri, B. P., Pastorelli, C., Eisenberg, N., Zuffiano, A., Castellani, V., \& Caprara, G. V. (2014). Trajectories of prosocial behavior from adolescence to early adulthood: Associations with personality change. Journal of Adolescence, 37, 701-713. https://doi.org/10.1016/j.adolescence.2014.03.013

Lynch, W. J., Piehl, K. B., Acosta, G., Peterson, A. B., \& Hemby, S. E. (2010). Aerobic exercise attenuates reinstatement of cocaine-seeking behavior and associated neuroadaptations in the prefrontal cortex. Biological Psychiatry, 68(8), 774-777. https://doi.org/10.1016/j.biopsych.2010.06.022 
Mahon, N. E., Yarcheski, A., Yarcheski, T. J., Cannella, B. L., \& Hanks, M. M. (2006). A meta-analytic study of predictors for loneliness during adolescence. Nursing Research, 55(5), 308-315. https://doi.org/10.1097/00006199-200609000-00003

Mamun, M. A., \& Griffiths, M. D. (2019). The assessment of internet addiction in Bangladesh: Why are prevalence rates so different?. Asian Journal of Psychiatry, 40, 46-47. https://doi.org/10.1016/j.ajp.2019.01.017

Martos, T., Sallay, V., Désfalvi, J., Szabó, T., \& Ittzés, A. (2014). [Psychometric characteristics of the Hungarian version of the Satisfaction with Life Scale (SWLS-H)]. Mentálhigiéné és Pszichoszomatika, 15, 289-303. https://doi.org/10.1556/Mental.15.2014.3.9

Milani, L., Osualdella, D., \& Di Blasio, P. (2009). Quality of interpersonal relationships and problematic Internet use in adolescence. Cyberpsychology \& Behavior, 12(6), 681-684. https://doi.org/10.1089/cpb.2009.0071

Morrison, C. M., \& Gore, H. (2010). The relationship between excessive Internet use and depression: a questionnaire-based study of 1,319 young people and adults. Psychopathology, 43(2), 121-126. https://doi.org/10.1159/000277001

Nunnally, J. (1994). Psychometric theory (3rd ed.). MacGraw-Hill.

O’Halloran, P., Kingsley, M., Nicholson, M., Staley, K., Randle, E., Wright, A., \& Bauman, A. (2020). Responsiveness of the single item measure to detect change in physical activity. Plos One, 15(6), e0234420. https://doi.org/10.1371/journal.pone.0234420

Papp-Zipernovszky, O., Kékesi, M. Z., \& Jámbori, S. (2017). [Hungarian validation of the Multidimensional Scale of Perceived Social Support (MSPSS)]. Mentálhigiéné és Pszichoszomatika, 18(3), 230-262. https://doi.org/10.1556/0406.18.2017.011

Park, M. H., Park, E. J., Choi, J., Chai, S., Lee, J. H., Lee, C., \& Kim, D. J. (2011). Preliminary study of Internet addiction and cognitive function in adolescents based on IQ tests. Psychiatry Research, 190(2-3), 275281. https://doi.org/10.1016/j.psychres.2011.08.006

Peltzer, K., Pengpid, S., \& Apidechkul, T. (2014). Heavy Internet use and its associations with health risk and health-promoting behaviours among Thai university students. International Journal of Adolescent Medicine and Health, 26(2), 187-194. https://doi.org/10.1515/ijamh-2013-0508

Prievara, D. K., Piko, B. F., \& Luszczynska, A. (2019). Problematic Internet use, social needs, and social support among youth. International Journal of Mental Health and Addiction, 17, 1008-1019. https://doi.org/10.1007/s11469-018-9973-x

Podsakoff, P. M., MacKenzie, S. B., \& Podsakoff, N. P. (2012). Sources of method bias in social science research and recommendations on how to control it. Annual Review of Psychology, 63(1), 539-569. https://doi:10.1146/annurev-psych-120710-100452

Punamäki, R. L., Wallenius, M., Nygård, C. H., Saarni, L., \& Rimpelä, A. (2007). Use of information and communication technology (ICT) and perceived health in adolescence: the role of sleeping habits and waking-time tiredness. Journal of Adolescence, 30(4), 569-585. https://doi.org/10.1016/j.adolescence.2006.07.004

Reed, P., Vile, R., Osborne, L. A., Romano, M., \& Truzoli, R. (2015). Problematic Internet usage and immune function. PloS One, 10(8), e0134538. https://doi.org/10.1371/journal.pone.0134538

Rosenberg M. (1965). Society and the adolescent self-image. Princeton University Press. 
Saikia, A. M., Das, J., Barman, P., \& Bharali, M. D. (2019). Internet addiction and its relationships with depression, anxiety, and stress in urban adolescents of Kamrup district, Assam. Journal of Family \& Community Medicine, 26(2), 108-112. https://doi.org/10.4103/jfcm.JFCM_93_18

Sayll, U., Vehid, S., \& Erginöz, E. (2021). Problematic Internet use in Turkish high school students: prevalence and related factors. American Journal of Health Behavior, 45(1), 31-43. https://doi.org/10.5993/AJHB.45.1.3

Siomos, K., Floros, G., Fisoun, V., Evaggelia, D., Farkonas, N., Sergentani, E., Lamprou, M., \& Geroukalis, D. (2012). Evolution of Internet addiction in Greek adolescent students over a two-year period: the impact of parental bonding. European Child \& Adolescent Psychiatry, 21(4), 211-219. https://doi.org/10.1007/s00787-012-0254-0

Susánszky, É., Konkolÿ Thege, B., Stauder, A., \& Kopp, M. (2006). [Validation of the short (5-item) version of the WHO Well-Being Scale based on a Hungarian representative health survey, Hungarostudy 2002]. Mentálhigiéné és Pszichoszomatika, 7(3), 247-255. https://doi.org/10.1556/Mental.7.2006.3.8

Topp, C. W., Østergaard, S. D., Søndergaard, S., \& Bech, P. (2015). The WHO-5 Well-Being Index: a systematic review of the literature. Psychotherapy and Psychosomatics, 84(3), 167-176. https://doi.org/10.1159/000376585

Tsitsika, A., Critselis, E., Kormas, G., Filippopoulou, A., Tounissidou, D., Freskou, A., Spiliopoulou, T., Louizou, A., Konstantoulaki, E., \& Kafetzis, D. (2009). Internet use and misuse: a multivariate regression analysis of the predictive factors of internet use among Greek adolescents. European Journal of Pediatrics, 168(6), 655-665. https://doi.org/10.1007/s00431-008-0811-1

Tsitsika, A. K., Andrie, E. K., Psaltopoulou, T., Tzavara, C. K., Sergentanis, T. N., Ntanasis-Stathopoulos, I., Bacopoulou, F., Richardson, C., Chrousos, G. P., \& Tsolia, M. (2016). Association between problematic internet use, socio-demographic variables and obesity among European adolescents. European Journal of Public Health, 26(4), 617-622. https://doi.org/10.1093/eurpub/ckw028

van den Eijnden, R. J., Meerkerk, G. J., Vermulst, A. A., Spijkerman, R., \& Engels, R. C. (2008). Online communication, compulsive Internet use, and psychosocial well-being among adolescents: a longitudinal study. Developmental Psychology, 44(3), 655-665. https://doi.org/10.1037/00121649.44.3.655

van den Eijnden, R. J., Spijkerman, R., Vermulst, A. A., van Rooij, T. J., \& Engels, R. C. (2010). Compulsive internet use among adolescents: bidirectional parent-child relationships. Journal of Abnormal Child Psychology, 38(1), 77-89. https://doi.org/10.1007/s10802-009-9347-8

Vanhalst, J., Luyckx, K., Teppers, E., \& Goossens, L. (2012). Disentangling the longitudinal relation between loneliness and depressive symptoms: Prospective effects and the intervening role of coping. Journal of Social and Clinical Psychology, 31, 810-834. https://doi.org/10.1521/jscp.2012.31.8.810

Wallis, D. (1997, January 6). Just Click No. The New Yorker. https://www.newyorker.com/magazine/1997/01/13/just-click-no

Wang, H., Zhou, X., Lu, C., Wu, J., Deng, X., \& Hong, L. (2011). Problematic Internet use in high school students in Guangdong Province, China. PloS One, 6(5), e19660. https://doi.org/10.1371/journal.pone.0019660

Wiederhold B. K. (2016). Low self-esteem and teens' Internet addiction: What have we learned in the last 20 years?. Cyberpsychology, Behavior and Social Networking, 19(6), 359. https://doi.org/10.1089/cyber.2016.29037.bkw

WHO. (1998). Wellbeing measures in primary health care/The Depcare Project. WHO Regional Office for Europe: Copenhagen. 
Xu, J., Shen, L. X., Yan, C. H., Hu, H., Yang, F., Wang, L., Kotha, S. R., Ouyang, F., Zhang, L. N., Liao, X. P., Zhang, J., Zhang, J. S., \& Shen, X. M. (2014). Parent-adolescent interaction and risk of adolescent internet addiction: a population-based study in Shanghai. BMC Psychiatry, 14, 112. https://doi.org/10.1186/1471-244X-14-112

Yang, S. C. \& Tung Ch.-J. (2007). Comparison of Internet addicts and non-addicts in Taiwanese high school. Computers in Human Behavior, 23(1), 79-96. https://doi.org/10.1016/j.chb.2004.03.037

Yang, L., Sun, L., Zhang, Z., Sun, Y., Wu, H., \& Ye, D. (2014). Internet addiction, adolescent depression, and the mediating role of life events: finding from a sample of Chinese adolescents. International Journal of Psychology, 49(5), 342-347. https://doi.org/10.1002/ijop.12063

Young K. S. (1996). Psychology of computer use: XL. Addictive use of the Internet: a case that breaks the stereotype. Psychological Reports, 79(3 Pt 1), 899-902. https://doi.org/10.2466/pr0.1996.79.3.899

Young, K. S. (1998). Internet addiction: The emergence of a new clinical disorder. CyberPsychology \& Behavior, 1(3), 237-244. https://doi.org/10.1089/cpb.1998.1.237

Yu, L., \& Shek, D. T. (2013). Internet addiction in Hong Kong adolescents: a three-year longitudinal study. Journal of Pediatric and Adolescent Gynecology, 26(3 Suppl), S10-S17. https://doi.org/10.1016/j.jpag.2013.03.010

Zimet, G. D., Dahlem, N. W., Zimet, S. G., \& Farley, G. K. (1988). The multidimensional scale of perceived social support. Journal of Personality Assessment, 52(1), 30-41. https://doi.org/10.1207/s15327752jpa5201_2

Correspondence: Andrea Lukács, Faculty of Healthcare, University of Miskolc, 3515 Miskolc-Egyetemváros, Hungary. E-mail: andrea.lukacs8080@gmail.com 